Tight glycaemic control can be implemented in the acute medical unit outside the intensive care setting with similar efficacy and risks of hypoglycaemia as those seen in ICU studies. ${ }^{30}$ However, optimal glycaemic control in COPD remains unclear and ICU studies have shown us that intensive strategies should not be adopted without rigorous testing in multicentre clinical trials.

In their paper, Chakrabarti and colleagues wisely steer clear of discussing the sticky issue of glycaemic control during COPD exacerbations. Rather they concentrate on the interesting finding that blood glucose $<7 \mathrm{mM}$ in combination with respiratory rate $<30 / \mathrm{min}$ predicted a successful outcome from NIV in $97 \%$ of patients with acute hypercapnic respiratory failure. Treatment failure was more likely (but not inevitable) in those with respiratory rate $>30 / \mathrm{min}$ and hyperglycaemia. If their findings are confirmed in other patient cohorts, this simple prognostic index could support discussions with COPD patients and their families prior to initiation of NIV and allow targeting of more intensive monitoring and treatment for those at greater risk of NIV failure. However, measurement of blood glucose is not currently part of NICE/BTS (National Institute for Health and Clinical Excellence/British Thoracic Society) guidelines for the management of COPD exacerbations, ${ }^{31}$ and data about blood glucose were not collected in the 2008 national COPD audit. This paper adds to the growing evidence that hyperglycaemia is important during COPD exacerbations and supports inclusion of blood glucose assessment in future recommendations. However, it does not clarify underlying mechanisms or make the case for tight glycaemic control, both of which require further study.

\section{Competing interests: None.}

Provenance and peer review: Commissioned; not externally peer reviewed.

\section{REFERENCES}

1. Baker EH, Wood DM, Brennan AL, et al. Hyperglycaemia and pulmonary infection. Proc Nutr Soc 2006;65:227-35.

2. Capes SE, Hunt D, Malmberg K, et al. Stress hyperglycaemia and increased risk of death after myocardial infarction in patients with and without diabetes: a systematic overview. Lancet 2000;355:773-8.

3. Capes SE, Hunt D, Malmberg K, et al. Stress hyperglycemia and prognosis of stroke in nondiabetic and diabetic patients: a systematic overview. Stroke 2001;32:2426-32.

4. Yendamuri S, Fulda GJ, Tinkoff GH. Admission hyperglycemia as a prognostic indicator in trauma. J Trauma 2003;55:33-8.

5. McAlister FA, Majumdar SR, Blitz S, et al. The relation between hyperglycemia and outcomes in 2,471 patients admitted to the hospital with community-acquired pneumonia. Diabetes Care 2005:28:810-5.

6. Baker EH, Janaway $\mathrm{CH}$, Philips BJ, et al. Hyperglycaemia is associated with poor outcomes in patients admitted to hospital with acute exacerbations of chronic obstructive pulmonary disease. Thorax 2006:61:284-9.

7. Ram FS, Picot J, Lightowler J, et al. Non-invasive positive pressure ventilation for treatment of respiratory failure due to exacerbations of chronic obstructive pulmonary disease. Cochrane Database Syst Rev 2004;(3):CD004104.

8. Moretti M, Cilione C, Tampieri A, et al. Incidence and causes of non-invasive mechanical ventilation failure after initial success. Thorax 2000;55:819-25.

9. Chakrabarti B, Angus RM, Agarwal S, et al. Hyperglycaemia as a predictor of outcome during non invasive ventilation in decompensated COPD. Thorax 2009;64:857-62

10. Adrogue HJ, Chap Z, Okuda Y, et al. Acidosis-induced glucose intolerance is not prevented by adrenergic blockade. Am J Physiol 1988;255:E812-23.

11. Esposito K, Nappo F, Marfella R, et al. Inflammatory cytokine concentrations are acutely increased by hyperglycemia in humans: role of oxidative stress. Circulation 2002;106:2067-72.

12. Andreozzi F, Succurro E, Mancuso MR, et al. Metabolic and cardiovascular risk factors in subjects with impaired fasting glucose: the 100 versus $110 \mathrm{mg} / \mathrm{dL}$ threshold. Diabetes Metab Res Rev 2007;23:547-50.

13. Choi KM, Lee J, Lee KW, et al. Comparison of serum concentrations of C-reactive protein, TNF-alpha, and interleukin 6 between elderly Korean women with normal and impaired glucose tolerance. Diabetes Res Clin Pract 2004;64:99-106.

14. Loukides S, Polyzogopoulos D. The effect of diabetes mellitus on the outcome of patients with chronic obstructive pulmonary disease exacerbated due to respiratory infections. Respiration 1996;63:170-3.

15. Philips BJ, Redman J, Brennan A, et al. Glucose in bronchial aspirates increases the risk of respiratory MRSA in intubated patients. Thorax 2005;60:761-4.

16. Brennan AL, Gyi KM, Wood DM, et al. Airway glucose concentrations and effect on growth of respiratory pathogens in cystic fibrosis. J Cyst Fibros 2007;6:101-9.

17. Brennan AL, Baines DL, Woollhead A, et al. Development of an in vitro model to investigate the effect of glucose on the interaction between respiratory epithelia and bacterial pathogens. Thorax 2006;61(Suppl II):ii101

18. Spruit MA, Gosselink R, Troosters T, et al. Muscle force during an acute exacerbation in hospitalised patients with COPD and its relationship with CXCL8 and IGF-I. Thorax 2003:58:752-6.

19. Martinez-Llorens JM, Orozco-Levi M, Masdeu MJ et al. [Global muscle dysfunction and exacerbation of COPD: a cohort study]. Med Clin (Barc) 2004;122:521-7.

20. Vanhorebeek I, De VR, Mesotten D, et al. Protection of hepatocyte mitochondrial ultrastructure and function by strict blood glucose control with insulin in critically ill patients. Lancet 2005:365:53-9.

21. Van den Berghe G, Wouters P, Weekers F, et al. Intensive insulin therapy in the critically ill patients. N Engl J Med 2001;345:1359-67.

22. Van den Berghe G, Wilmer A, Hermans G, et al Intensive insulin therapy in the medical ICU. N Engl J Med 2006;354:449-61.

23. Hansen TK, Thiel S, Wouters PJ, et al. Intensive insulin therapy exerts antiinflammatory effects in critically ill patients and counteracts the adverse effect of low mannose-binding lectin levels. J Clin Endocrinol Metab 2003;88:1082-8.

24. Hemmila MR, Taddonio MA, Arbabi S, et al. Intensive insulin therapy is associated with reduced infectious complications in burn patients. Surgery 2008;144:629-37.

25. Ellger B, Richir MC, Van Leeuwen PA, et al. Glycemic control modulates arginine and asymmetricaldimethylarginine levels during critical illness by preserving dimethylarginine-dimethylaminohydrolase activity. Endocrinology 2008:149:3148-57.

26. Biolo G, De CM, Lorenzon S, et al. Treating hyperglycemia improves skeletal muscle protein metabolism in cancer patients after major surgery. Crit Care Med 2008;36:1768-75.

27. Finfer S, Chittock DR, Su SY, et al. Intensive versus conventional glucose control in critically ill patients. $N$ Engl J Med 2009;360:1283-97.

28. Griesdale DE, de Souza RJ, van Dam RM, et al. Intensive insulin therapy and mortality among critically ill patients: a meta-analysis including NICE-SUGAR study data. CMAJ 2009:180:821-7.

29. Bellomo R, Egi M. What is a NICE-SUGAR for patients in the intensive care unit? Mayo Clin Proc 2009;84:400-2.

30. Archer JA, Misra S, Getov S, et al. Feasibility and safety of tight glycaemic control outside the intensive care setting. Br J Clin Pharmacol 2009; in press (abstract).

31. National Collaborating Centre for Chronic Conditions. Chronic obstructive pulmonary disease. National clinical guideline on management of chronic obstructive pulmonary disease in adults in primary and secondary care. Thorax 2004;59(Suppl 1):1-232.

\title{
Identification of those at risk after acute pulmonary embolism
}

\section{Andrew J Fisher, Paul A Corris}

Northern Pulmonary Vascular Unit, Freeman Hospital and Institute of Cellular Medicine, The Medical School, Newcastle University, Newcastle upon Tyne, UK
Correspondence to: Professor A J Fisher, Institute of Cellular Medicine, The Medical School, Newcastle University, Newcastle upon Tyne NE2 4HH, UK a.j.fisher@newcastle.ac.uk
It is well recognised by hands-on clinicians that patients who present acutely with haemodynamic compromise and hypotension with a systolic pressure of $<90 \mathrm{~mm} \mathrm{Hg}$ due to acute pulmonary embolism (PE) have a poor prognosis. This is reflected in current British Thoracic Society guidelines in the management of acute PE which recommend 
aggressive interventions in this population, with thrombolysis as first-line treatment. ${ }^{1}$

However, stratification of mortality and morbidity risk in normotensive patients who present with acute $\mathrm{PE}$ is less clear. Demonstration of right ventricular dysfunction or dilatation on either echocardiography or spiral HRCT scanning of the chest has been used as a potential indicator of those requiring more aggressive treatment even if normotensive. Immediate availability of these modalities is not universal, and a simpler way of identifying those patients at highest risk of adverse events and mortality remains critical as the inpatient mortality rate for normotensive patients with acute $\mathrm{PE}$ is approximately $10 \%{ }^{2}$ A number of previous studies have attempted to identify biomarkers which have prognostic power in patients with acute PE. Many of these studies have focused on cardiac biomarkers including the troponins and natriuretic peptides which correlate with right ventricular dysfunction on echocardiography. ${ }^{3}$ Whether these systemic biomarkers correlate with an increased risk of poor outcome in patients has been the subject of debate and, at present, there is no clear consensus as to the predictive value of cardiac biomarkers as a guide to risk stratification in this population.

The recent European Society of Cardiology guidelines on the diagnosis and management of acute pulmonary embolus published in 2008 have gone as far as including raised levels of the B-type natriuretic peptides BNP or NT-proBNP and increased cardiac troponins as markers of increased risk of a poor outcome due to PE-related mortality. ${ }^{4}$

In this issue of Thorax, Lega and colleagues $^{5}$ from Quebec, Canada and Lyons, France present a very comprehensive and methodologically robust metaanalysis of the prognostic value of natriuretic peptides and troponins in acute PE (see page 869). This is an extremely important piece of work, which brings together results of a large number of studies in this area. In addition to identifying all published studies capable of evaluation, the authors went to great lengths to minimise publication bias by examining all the abstract presentations at major international respiratory meetings over the last 10 years. In this metaanalysis, the methodological quality of the included studies was systematically reviewed to look for any evidence of selection bias, information bias, where the results of cardiac biomarker measurement influenced management and confounding bias and where other diseases such as renal failure or chronic heart failure may have influenced a result. One of the difficulties in comparing the results of the included studies is the range of different assays used to measure the natriuretic peptides. Four different assays were identified and different studies used different thresholds to define positive and negative results. In many, the definition of a positive or negative result was made at the end of the study based on receiver operating curve analysis. Despite these limitations, the results show that raised levels of B-type natriuretic peptides are associated with an increased risk of mortality, serious adverse events and right ventricular dysfunction after PE. This association also importantly appears to hold true for both haemodynamically stable and unstable patients at presentation. It also appears to be robust even in the presence of co-factors such as chronic heart failure and renal failure. The metaanalysis did, however, suggest that BNP measurement appeared to be more accurate than NT-proBNP in correlating with right ventricular dysfunction.

A previous meta-analysis has been published in this area. Work by Becattini and colleagues showed that positive troponins correlated with right ventricular myocardial damage and with poor outcomes after acute PE. ${ }^{6}$ The paper by Lega and colleagues adds to the existing literature by the robustness of its analysis and the careful search for studies. Specifically, this meta-analysis also considered the combined benefit of troponin and natriuretic peptide measurement. When a combination of natriuretic peptide and troponin measurement is used to stratify risk, the study shows that, in patients with an increase in natriuretic peptide, additional elevation of troponins is associated with a further increase in PE-related mortality and serious adverse events. Importantly, this held true when haemodynamically stable patients were considered for all-cause mortality with an odds ratio of 6.9 (confidence interval 2.3 to 20.7) and acute PE-related mortality odds ratio 8.4 (confidence interval 2.1 to 33.4 ).

This study offers very useful insights into risk stratification in normotensive patients presenting with acute PE. Its timing is particularly important as there is growing interest in the outpatient management of individuals presenting with acute PE who are haemodynamically stable. In light of the still high hospital mortality in this group, it is important that every effort is made to identify those at the highest risk who would be unsuitable for outpatient management. The measurement of natriuretic peptides and troponins in this population may not only be able to identify those patients at highest risk but also, conversely, if the natriuretic peptide level is normal, provide reassurance that a lower risk patient is eligible for outpatient management. This is very much the case with supportive evidence from this study showing that "natriuretic peptides are particularly helpful in identifying low-risk patients".

There are caveats on the conclusions drawn from this meta-analysis. It is important to recognise that the conclusions give the rationale for a large-scale prospective multicentre randomised trial of cardiac biomarkers to stratify risk in PE. Possible interventions in such a study could include early thrombolysis in haemodynamically stable patients that have yet to undergo formal assessment for right ventricular dysfunction, inpatient anticoagulation and close observation and outpatient anticoagulation.

The authors should be congratulated on their valuable contribution to this important debate, and it is hoped those involved in research into acute PE will take this information forward in the design of clinical trials to provide some more definitive answers linking risk stratification, intervention and prospective outcomes in this group of patients.

Competing interests: None.

Provenance and peer review: Commissioned; not externally peer reviewed.

Thorax 2009;64:832-833. doi:10.1136/thx.2009.114009

\section{REFERENCES}

1. British Thoracic Society. BTS guidelines for the management of suspected acute pulmonary embolism. Thorax 2003:58:470-84.

2. Bova C, Pesavento R, Marchiori A, et al. Risk stratification and outcomes in hemodynamically stable patients with acute pulmonary embolus: a prospective, multi-centre, cohort with three months follow-up. J Thromb Haemost 2209; 7:938-44

3. Kostrubiec M, Pruszczyk $P$, Bochowicz $A$, et al. Biomarker-based risk assessment in acute pulmonary embolism. Eur Heart J 2005;26:2166-72.

4. Torbicki A, Perrier A, Konstantinidis S, et al. Guidelines on the diagnosis and management of acute pulmonary embolus. European Society of Cardiology. Eur Heart J 2008;29:2276-315.

5. Lega J-C, Lacasse Y, Lakhal L, et al. Natriuretic peptides and troponins in pulmonary embolism: a meta-analysis. Thorax 2009;64:869-75.

6. Becattini C, Vedovati MC, Agnelli G. Prognostic value of troponins in acute pulmonary embolus: a metaanalysis. Circulation 2007;116:427-33. 